Mariana Palumbo

Universidad de Buenos Aires, Buenos Aires, Buenos Aires, Argentina

\title{
Experiencias de amor y violencia en los primeros noviazgos juveniles
}

Resumen: La hipótesis de trabajo de la siguiente investigación se basa en que en los noviazgos de jóvenes heterosexuales de clase media del Área Metropolitana de Buenos Aires (AMBA) existe una tensión entre la violencia y el amor de pareja. Con el fin de abordar esta hipótesis, se desarrolla una propuesta teórico metodológica que permita problematizar e interrelacionar a ambos conceptos. Luego, a la luz de dicha perspectiva, se analizan escenas de violencia que se enmarcan, según la perspectiva de los propios actores, dentro un registro de juego y amor; y escenas que permiten visualizar el pasaje de momentos de pelea a momentos de placer en la pareja.

Palabras claves: violencia contra las mujeres; amor; agencia; intensidad.

\section{Introducción}

"Si te pega no te ama". Una serie de preguntas se hacen presentes para complejizar dicha afirmación, tales como: ¿se puede pensar la violencia por fuera del amor? ¿Será que la violencia existe porque la forma en la que amamos la incluye? ¿Decir que el amor todo lo puede, equivale a pensar que en el amor todo está permitido? Y en tal caso, ¿cuál es su límite? ¿Cómo perciben los jóvenes que están de novios, en sus relatos, sus peleas? ¿Cómo aman?

En las siguientes páginas, desarrollo un análisis de fragmentos de entrevistas en las cuales intento echar luz sobre estos interrogantes a partir de la descripción de escenas (PAIVA, 2006) de interacciones de noviazgo en jóvenes de clase media del Área Metropolitana de Buenos Aires (AMBA), con el objetivo de describir y analizar cómo la violencia constituye a las interacciones dentro de las relaciones amorosas, y cómo el amor está atravesado por la violencia.'

Esta obra está sob licença Creative Commons.

${ }^{1}$ Sin desconocer que intervienen en estas interacciones otros condicionantes estructurales como el mercado en este artículo me propongo describir y analizar las dinámicas entre amor y violencia al momento de las interacciones de noviazgo cotidianas de estos jóvenes. 
La hipótesis que guió este abordaje ${ }^{2}$ se basó en que en los noviazgos de jóvenes heterosexuales de clase media urbana de clase media del Área Metropolitana de Buenos Aires (AMBA) existe una tensión entre la violencia y el amor de pareja. La coexistencia de ambos conceptos se encuentra en el propio discurso amoroso el cual es fragmentario y discontinuo (Roland BARTHES, 2001; Georges BATAILLE, 2010; María Filomena GREGORI, 1993, 2003). Esto me llevo a plantear una hipótesis que estipule ambos conceptos interrelacionados, en tensión (Georg SIMMEL, 1939). ${ }^{3}$ La misma se basa en que en los noviazgos de jóvenes heterosexuales de clase media urbana de clase media del Área Metropolitana de Buenos Aires (AMBA) existe una tensión entre la violencia y el amor de pareja. ${ }^{4}$

El interés en estudiar las dinámicas del amor y la violencia en los jóvenes provino de que es allí cuando comienzan a ponerse en práctica y a establecerse los sentidos que otorgan estos jóvenes al modo en que aman. Por lo que, si se quiere pensar y/o prevenir la violencia en las parejas, resulta indispensable el análisis de esas primeras experiencias de noviazgo.

Para Oscar Dávila León (2005), desde una dimensión sociodemográfica, ${ }^{5}$ convencionalmente la juventud se ha ubicado dentro de la franja etaria entre los 15 y 29 años de edad, aproximadamente, la cual a su vez se divide de 15 a 19 años, de 20 a 24 años y de 25 a 29 años. Me baso en el primer subtramo debido a que me propongo indagar en las interacciones de los primeros noviazgos, y a que éste contiene a aquella población en situación de escolarización o que terminó el nivel educativo secundario hace menos de un año. ${ }^{6}$

Asimismo, retomo la propuesta de Silvia Elizalde de ponderar el género en los estudios sobre juventud, sin ser pensado como un mero sinónimo de diferencia sexual o como simple dato demográfico, para no aportar así a "Ia enraizada propensión a considerar tácitamente a los varones como sujetos de referencia de "la juventud»" (ELIZALDE, 2006, p. 6). Es decir,

\footnotetext{
${ }^{2}$ Este artículo se desprende de los resultados obtenidos en mi tesis de Maestría denominada "Las dinámicas de la violencia contra las mujeres y el amor en los primeros noviazgos juveniles en el Área Metropolitana de Buenos Aires". Con el fin de analizar esta hipótesis, desde un abordaje cualitativo, se describieron, por un lado, las dinámicas de la violencia contra las mujeres en relación con el amor, que se manifiestan en ciertas relaciones de noviazgo heterosexuales juveniles de clase media; $y$, por otro lado, los efectos que estas dinámicas generan sobre los cuerpos de los jóvenes que están de novios. Un artículo con resultados preliminares fue publicado en la Revista Argumentos. Revista de Crítica Social, en el año 2016.

${ }_{3}^{3}$ Para Georg Simmel existen diversas polaridades en tensión que no conllevan necesariamente un tercer momento o superación. En el segundo a priori de su Sociología grande, el autor presenta una doble situación del individuo: la de ser un ser para la sociedad y un ser para sí mismo. Pero esta dualidad no implica escisión sino que ambas constituyen a su vez una unidad, la del ser social (SIMMEL, 1939).

${ }^{4}$ Este artículo se desprende de los resultados obtenidos en mi tesis de Maestría denominada "Las dinámicas de la violencia contra las mujeres y el amor en los primeros noviazgos juveniles en el Área Metropolitana de Buenos Aires" con el fin de analizar esta hipótesis, desde un abordaje cualitativo, se describieron, por un lado, las dinámicas de la violencia contra las mujeres en relación con el amor, que se manifiestan en ciertas relaciones de noviazgo heterosexuales juveniles de clase media; $y$, por otro lado, los efectos que estas dinámicas generan sobre los cuerpos de los jóvenes que están de novios.

${ }^{5}$ En el campo de las disciplinas científicas se ha dividido la pertinencia de la utilización de los conceptos de adolescencia y juventud; el primero es abordado por la psicología en tanto perspectiva de análisis de un sujeto particular; y el segundo, por las ciencias sociales y humanas, donde a partir de sujetos individuales se busca entender las relaciones sociales posibles de ser entabladas entre ellos (DÁVILA LEÓN, 2005).

${ }^{6}$ En términos generacionales, los/as entrevistados/as nacieron entre 1995 y 1999 en la Argentina, por lo que siempre han vivido en un régimen político democrático. En el mismo se ha promulgado la "Ley de protección integral para prevenir, sancionar y erradicar la violencia contra las mujeres en los ámbitos en que desarrollen sus relaciones interpersonales", la cual define e incluye los diferentes tipos de violencia contra las mujeres y los ámbitos donde se manifiestan.
} 
por un lado, visibilizo a las mujeres de clase media como agentes jóvenes que producen prácticas y sentidos específicos vinculados a la violencia en las relaciones amorosas juveniles; $y$, por el otro, tengo en cuenta al momento del análisis de los objetivos planteados los entramados de poder entre los jóvenes, provenientes de las estructuras de género en las cuales se encuentran insertos. ${ }^{7}$

En relación con la perspectiva teórica del artículo, es interaccionista (Erving GOFFMAN, $1970,1971)$. Goffman comprende a la interacción como "Ia influencia recíproca de un individuo sobre las acciones del otro cuando se encuentran ambos en presencia física inmediata" (GOFFMAN, 1971, p. 27). Cuando al menos dos personas interactúan cara a cara, influencian recíprocamente sus acciones, de manera que el actor guiará su actuación ajustándose a los papeles representados por los otros actores, que a su vez son su público. Siguiendo este razonamiento, en las discusiones y escenas amorosas que aquí se estudian, los agentes se aceptan temporariamente en lo que vale ese encuentro social.

Por último, la metodología de la investigación es cualitativa, pues son objeto de indagación los sentidos de las prácticas y las representaciones respecto del amor y la violencia contra las mujeres que poseían los sujetos a ser entrevistados. Para ello, se llevaron a cabo quince entrevistas en profundidad a jóvenes de clase media ${ }^{8}$ a partir de la técnica de la bola de nieve, entre los años 2012-2014, que me habilitaron a interpelar a estos sujetos sopesando su singularidad como productores de significados y sentidos sobre sus

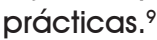

En el desarrollo de las entrevistas, utilicé la metodología de las escenas de Vera Paiva (2006) la cual apunta a que los/as entrevistados/as relaten, como si fuesen guionistas de su propia película, circunstancias y escenas prototípicas de su vida cotidiana de pareja, con el fin de analizar no sólo las creencias y representaciones que poseen, sino también las sensaciones y sentidos que mediaron en su experiencia. Según Vera Paiva, las escenas son herramientas metodológicas que permiten organizar el recuerdo sobre lo que sucedió. A partir de las preguntas que iba haciendo, estimulé a que se describa el espacio de la

\footnotetext{
${ }^{7}$ Silvia Elizalde (2006), desde una perspectiva materialista, se encuentra en discusión con el concepto de juventud desarrollado desde la sociología por Mario Margulis y Marcelo Urresti $(1996,2006)$. Estos autores, quienes lo han interpretado como una construcción social, histórica y relacional que se articula social y culturalmente en función de la edad, la generación, la clase social y el género de pertenencia (MARGULIS y URRESTI, 1996), consideran el género, según Elizalde, como una variable más en relación al concepto de juventud. Para la autora, esa posición tiene consecuencias de orden ideológico que operan ratificando el androcentrismo y sus efectos naturalizantes porque abordan el género como un atributo que poseen las personas, anclado en un binarismo taxativo de sexo/género, y se hace así caso omiso al carácter político de esta categoría de análisis como forma primaria de relaciones significantes de poder (Joan SCOTT, 1986).

${ }^{8}$ Daniel Jones (2010) define a los adolescentes, en su libro sobre sexualidades adolescentes de jóvenes de clase media, según su ubicación familiar, dado que viven en las casas de sus padres y ocupan en ellas el lugar de hijos (KAPLÚN, 2004); son mantenidos por sus padres para realizar sus diferentes actividades sociales, y por su sociabilidad, pasan la mayor parte de su tiempo con sus pares, en la escuela o en lugares de esparcimiento.

${ }^{9}$ Las mismas fueron realizadas en cafés, plazas y restaurantes, de común acuerdo, sin la presencia de terceros. Los jóvenes entrevistados comparten los siguientes rasgos: se identifican como heterosexuales viven en la casa de sus progenitores/as o tutores y en ésta ocupan el lugar de hijos, no tienen hijos, cursan la escuela media o han terminado la educación media hace menos de un año, pasan la mayor parte de su tiempo con sus pares, la escuela y en ámbitos de esparcimiento, son de clase media, tienen al me nos tres meses de noviazgo al momento que realicé la entrevista, el lugar de residencia es el AMBA, y, por último, tienen entre 15 y 19 años. Las entrevistas se realizaron de la siguiente manera: a) cinco, a mujeres que estén de novias; b) cinco, a varones que estén de novios; c) cinco, a parejas. Respeté la voluntariedad y confidencialidad en las entrevistas a través de la utilización de seudónimos, y la protección de cualquier dato potencialmente sensible.
} 
escena, el tiempo, las personas que estaban presentes en ella y el ritmo en el cual la misma sucedía, como así también una descripción sobre los detalles de las prácticas e interacciones (PAIVA, 2006). La noción de escena, en tanto permite abordar la propia experiencia de los actores, es rica para poder desarrollar un análisis sobre la agencia de los actores, analizar cómo intervienen cada uno de los sujetos en las dinámicas de la violencia y cómo la forma en la cual aman estos jóvenes genera situaciones de violencia, tal como presento en el análisis.

A partir de la apuesta teórica metodológica descripta, el siguiente artículo se estructura en tres secciones. En la primera examino un breve estado de la cuestión sobre la violencia contra las mujeres en sus vínculos interpersonales, y desarrollo una propuesta teórica que me permita pensar la tensión entre el amor y la violencia en las primeras relaciones de noviazgo juveniles. En el segundo y tercer apartado, analizo escenas relatadas en las entrevistas teniendo en cuenta la tensión existente entre el amor y la violencia. Para dicho fin, por un lado abordo escenas que se enmarcan dentro un registro de juego; y por el otro, aquellas que permiten visualizar conflictos que terminaron en una reconciliación, y analizo cómo las escenas de conflicto son relatadas por los/as entrevistados/as como quejas.

\section{Presupuestos teóricos para pensar la tensión entre amor y violencia}

En las siguientes páginas, esbozo un breve estado de la cuestión sobre la violencia contra las mujeres en sus vínculos interpersonales, y cuáles son las perspectivas teóricas en las cuales me baso para llevar a cabo un análisis de las relaciones de pareja en términos de tensión entre amor y violencia.

Las lecturas hegemónicas en el campo académico argentino sobre la violencia contra las mujeres indagan en las interacciones violentas poniendo el foco en el varón como agresor y en la mujer como agredida, y no problematiza en las correspondencias que existen entre las formas en que los sujetos aman y las prácticas violentas, que aparecen en los vínculos afectivos (Susana VELÁZQUEZ, 2006; María Luisa FEMENÍAS, 2009). Estas perspectivas, a los cuales denomino como victimizantes, entienden por violencia de género ${ }^{10}$ a "todos los actos mediante los cuales se discrimina, ignora, somete y subordina a las mujeres en los diferentes aspectos de su existencia. Es todo ataque material y simbólico que afecta su libertad, dignidad, seguridad, intimidad e integridad moral y/o física" (VELÁZQUEZ, 2003, p. 29).

En contraposición, Filomena Gregori (1993, 2003) y Miriam Grossi (1998) consideran que las mujeres pueden ser propulsoras de violencia al igual que sus parejas en el espacio afectivo/conyugal (Porto, 2014). Gregori, desde un análisis del erotismo de Georges Bataille (2010), comprende las escenas de discusión en las parejas heterosexuales teniendo en cuenta la existencia de una tensión entre placer y agresión. Los amantes se encuentran en una búsqueda constante para alcanzar una fusión, marcada por la intensidad. Dice Bataille: “(...) los momentos de intensidad son los momentos de exceso y de fusión de los

\footnotetext{
${ }^{10}$ La noción de violencia de género trasciende la violencia ejercida contra las mujeres e incluye a todos aquellos cuerpos que no se adecuan a la masculinidad hegemónica (R.W. CONNELL, 1995). La misma existe en tanto hay subordinación de otros grupos, que pueden ser las mujeres en su multiplicidad, pero también los hombres no heterosexuales, heterosexuales que no cumplen con los estereotipos esperados de masculinidad, o varones de color. Pero en este proyecto me centro específicamente en la violencia contra la s mujeres, por lo que utilizo mayormente el concepto de violencia contra las mujeres. No obstante, hago referencia a la categoría de violencia de género, dado que es el modo en que es teorizada por diferentes autoras la violencia contra las mujeres.
} 
seres" (BATAILLE, 2000, p. 105). A raíz de esa búsqueda se transgreden prohibiciones establecidas por el ámbito homogéneo. "1" No obstante, Bataille no pretende dicotomizar entre homogéneo y heterogéneo al punto de verlos como simples opuestos, sino verlos en coexistencia y entrelazados, tal como aquí se aborda al amor y a la violencia. En la búsqueda de la intensidad, los amantes transgreden prohibiciones que implican escenas de violencia dentro de la pareja y, que según he analizado, no implican necesariamente una ruptura del lazo afectivo.

Explica Gregori que el momento de la agresión allana el camino para el surgimiento de un nuevo momento, el del placer, la reconciliación, es decir, un pasaje de estado de divergencia a otro de convergencia (GREGORI, 1993). En la autora, la violencia es entendida como un acto de comunicación ${ }^{12}$ (BATAILLE, 2010) sustentado en distintas motivaciones: la búsqueda de la soberanía, disposiciones conflictivas de papeles cuyos desempeños esperados no son cumplidos, disposiciones psicológicas, tales como esperar de la pareja ciertas conductas, provocaciones de las mujeres del orden del inconsciente para que sus parejas masculinas reaccionen de una determinada manera, y juegos eróticos.

En este artículo retomo la definición de la violencia y las tipificaciones de Femenías (2009) y Velázquez (2006) para el análisis de las escenas de violencia que aquí analizo, pero, a su vez, complejizo quiénes son los agentes que perpetran violencia. Para dicho fin, retomo a Grossi (1998), Gregori $(1995,2003)$ y Raquel Osborne Verdugo $(2008,2009)$. Desde la noción de erotismo de Bataille (2010), comprendo que hay contextos de sentido y motivaciones que incluyen a ambos miembros de la pareja que permiten entender el amor vinculado a la violencia. Esto no implica justificar la violencia en tanto fue una provocación de una parte hacia la otra, sino que permite, por un lado, comprender el sentido por el cual se dan esos juegos y conductas de placer y agresión en un contexto específico; y por el otro, analizar qué las pautas de cortejo (COSSE, 2010) son consideradas como aceptables para estos jóvenes dentro de los umbrales de la relación y cuáles son percibidas como violentas.

En las siguientes páginas, analizo fragmentos de entrevistas donde se describen escenas (PAIVA, 2006) a partir de las cuales se puede reconstruir la tensión que existe entre el amor y la violencia en las interacciones de noviazgo de estos jóvenes, observando cómo la violencia constituye a las relaciones amorosas, y cómo el amor está atravesado por la violencia.

\section{Juegos de pareja: entre el amor y la violencia}

En el siguiente apartado, estudio comparativamente dinámicas que pueden ser enmarcadas como juegos en tanto generan en los jóvenes además de angustia, complicidad y diversión. Esto será desarrollado a partir de tres historias de noviazgo: la de Gustavo con su novia, la de Lara con su ex pareja - donde hubo escenas de violencia (al igual que con su pareja actual) - y la de Tamara y Hugo (quienes fueron entrevistados de forma conjunta).

Gustavo tenía 16 años al momento de la entrevista y hacía un año y ocho meses que se encontraba en pareja con una compañera del colegio. Cuando le pregunté acerca de

\footnotetext{
${ }^{11}$ Dentro del ámbito homogéneo se encuentra la razón, la mesura. Mientras que en lo heterogéneo, lo no homogéneo, se encuentra aquello excluido del deber ser socialmente estipulado, a saber, el erotismo y la violencia.

${ }^{12}$ Bataille diferencia entre comunicación débil y comunicación fuerte. La actividad habitual de los seres -lo que llamamos 'nuestras ocupaciones'- es distinta a la comunicación fuerte, que fundamentan las emociones de la senxsualidad y de las fiestas, que fundamentan el drama, el amor, la soberanía, la separación y la muerte (BATAILLE, 2000, p. 277).
} 
qué pensaba sobre su vínculo, para demostrarme el afecto que sentía por su novia me narró escenas de pelea o "de guerra toda", tal como las llama Gustavo, que él interpretaba como de juego y fraternidad. Comencemos por el análisis de este extenso fragmento.

$\mathrm{E}^{13}$.: ¿Y se llevan bien entre ustedes?

Gustavo: Sí, sí, somos como mejores amigos.

E.: ¿Cómo sería eso?

Gustavo: (...) O sea, lo que más hago con ella es molestarla, pero se ríe.

Me dice que pare.

E.: ¿Cómo la molestás? ¿Qué sería molestarla?

Gustavo: Ni idea, no sé, la molesto, qué sé yo.

E.: Un ejemplo.

Gustavo: ¿Un ejemplo? A ver, no sé, la molesto. Le rayo la cara, cosas así.

E.: ¿Con marcador?

Gustavo: Sí, sí, y ahí empieza una guerra toda, o cuando yo, por ejemplo a veces se queda a comer a casa cuando no están mis viejos y yo cocino y estoy cocinando y entra mi novia y le tiro un huevo, cosas así, la molesto.

E.: ¿Y ella esto cómo se lo toma?

Gustavo: Ella, primero me putea y después se tienta y me tira un huevo, es todo el tiempo así. Ella no se va a enojar por eso obviamente. $Y$ me gusta que se enoje porque yo después le voy a dar un abrazo, un beso y nos tentamos y ella me molesta a mí y cosas así.

E.: ¿Y ella qué te hace a vos?

Gustavo: Es medio grandota y me empuja, me empuja todo el tiempo.

E.: ¿Y te duele?

Gustavo: No, no me empuja tipo así como si fuera, o sea, por eso a veces como si yo fuera la mujer y ella es el hombre y cosas así, divertido.

E.: ¿Con qué otras cosas la molestás?

Gustavo: A veces está hablando con mi mamá y yo soy bastante zafado, no en público, pero ya con el entorno familiar sí. Soy medio guarango. Y ponele que ella está hablando con mamá y voy y le bajo los pantalones (risas).

E.: ¿Delante de tu mamá?

Gustavo: Sí, mi mamá me caga a pedos. Me dice que soy un pelotudo y cosas así. Mi novia se pone toda colorada y a mí me encanta, porque me gusta molestarla.

E.: ¿Qué pasa?

Gustavo: Me corre por toda la casa, hasta que me agarra y me pega. Me agarra así y me pega en el brazo. Yo tentado y ella tentada.

Para responder afirmativamente a esa pregunta Gustavo presenta dos escenas (PAIVA, 2006). En la primera, él está en la cocina de su casa disfrutando de un momento íntimo junto con su novia y sin la presencia de terceros. Mientras que en la segunda escena está con su novia pero interactuando en un ambiente familiar, con una tercera persona, su mamá. Aunque en una escena el escenario es íntimo y en la otra no, en ambas hay golpes, hacerle pasar al otro vergüenza (bajándole los pantalones delante de un familiar) y lastimarse. Estas situaciones son relatadas por el entrevistado como juegos de complicidad y de disfrute para él y, por lo que relata, para su novia también, aunque a su madre le parezca desubicado.

El acto de golpearse y rayarse la cara es relatado por Gustavo como un juego, al cual él define como de "guerra toda". Rozeli Maria Porto (2014) explica que para Gregori (1993) la violencia es un juego relacional en el cual hay una escena que prepara la guerra. "Las mujeres y los hombres provocan o mantienen estas situaciones,

${ }^{13}$ E. indica Entrevistadora.

1334 Estudos Feministas, Florianópolis, 25(3): 1329-1346, setembro-dezembro/2017 
inconscientemente o impensadamente, sin la intención clara o voluntad de, pero jugando con signos, diálogos, insultos o acusaciones que las estimulan" (GREGORI, 1993, p. 183185, citado en PORTO, 2014, p. 28). ${ }^{14}$ En esos actos, que son relatados por los jóvenes lúdicamente, ellos entran en fusión, disuelven formas constituidas del orden homogéneo que representaría en este caso la mirada de su madre. Se relacionan estableciendo pautas de cortejo y seducción (COSSE, 2010) que involucran un registro de lo violento. Las pautas de cortejo establecidas desde el ámbito de lo homogéneo (BATAILLE, 2010) como deseables descartan la violencia y conforman un ideal de amor inmaculado, el sufrimiento no es reconocido y se enfatiza, en el marco de una cultura hedonista (Eva ILLOUZ, 2009, 2010), la búsqueda de la felicidad y lo lúdico. No obstante, en la comunicación fuerte, en términos de Bataille (2010), en esa interacción donde la comunicación verbal queda de lado y se pone en juego la comunicación de las risas y los golpes, esta pareja entra en estado de continuidad, y reconocen allí cierto registro de la alegría y la complicidad.

Él dice que le gusta molestarla y que ella hace lo mismo. Justifica esas interacciones en que su vínculo es como de mejores amigos, lo cual remite a la noción de amor fraternal de Erich Fromm (2004). Este tipo de amor es un amor entre iguales: "hoy yo, mañana tú (...) no significa que uno sea desvalido y el otro poderoso" (FROMM, 2004, p. 67). El amor fraternal es la clase más fundamental de amor, dado que se encuentra en todos los tipos de amor. Por él se entiende el sentido de la responsabilidad, el cuidado y el respeto. Aunque para Fromm en la definición de amor erótico - de pareja - se encuentra presente el sentimiento de ternura, propia del amor fraternal, la resolución de estas escenas con abrazos y besos no se corresponde, en términos de Badiou (2012), con la amistad. Para Badiou (2012), el amor entre amigos no requiere necesariamente de pruebas corporales como sí sucede en el vínculo de pareja. Desde la apuesta teórica de Gregori (2003), considero que esta interacción remite más bien a la idea de un juego erótico aceptado por ambos que buscan el conflicto para luego acercarse sexualmente.

Los celos, el control - sobre el modo en el cual el otro se viste, con quienes salen de noche - y el miedo a la infidelidad son constantes en esta pareja. Sin embargo, como prueba de que son fieles, y por ende de reafirmar su relación, una interacción que aparece, relatada con risas por el entrevistado, es contarse uno al otro con qué otras personas, con las que ellos se relacionan diariamente, estarían erótica o afectivamente cuando no estén más juntos.

E.: ¿Eso que vos le decís si le gusta un chico y ella te dice a vos, se lo dicen todo el tiempo?

Gustavo: No, no, tampoco todo el tiempo. A veces estoy aburrido y tengo ganas de molestarla y le pregunto, porque es más para molestarla, para joderla, porque me divierte hacerla enojar. No me gusta hacerla enojar, tipo enojar feo. Me gusta como que se ponga medio histérica. Yo me divierto con eso. Me dice "dale, dale, no es gracioso" pero como riéndose, no es que se enoja en serio. Pero al otro día por ahí le pregunto lo mismo y me miente y ahí sí nos peleamos.

E.: ¿Cómo es que se ponga medio histérica?

Gustavo: Es medio histérica, es medio loca, es medio violenta todo el tiempo.

E.: ¿Por qué?

Gustavo: Porque no sé, es medio violenta.

E.: ¿En qué sentido?

\footnotetext{
14 "que as mulheres e os homens provocam ou mantêm estas situações, inconscientemente ou impensadamente, sem a intenção clara o vontade de, más jogando com signos, diálogos, xingamentos ou acusações que o estimulam" (GREGORI, 1993, p. 183-185, citado en PORTO, 2014, p. 38) [Traducción propia]
} 
Gustavo: Porque me pega. A veces me pega. No me duele tipo, depende, me rasguña, porque le hago esas preguntas y ella busca no pelear y yo la peleo, y nada, se pone histérica y no sé, la quiero mucho.

Esto que es planteado por Gustavo como un modo de divertirse ante el aburrimiento, como un juego, tiene un desarrollo específico. Este juego comienza con lo que los/as entrevistados/as denominan "jodas" que ponen a su novia "medio histérica", sin exceder el parámetro o el límite que daría fin al juego, el de hacerla "enojar feo". No obstante, esto no puede ser interpretado desde la lógica de un varón que ejerce poder sobre una mujer, sino que ella también lo golpea. Este tipo de interacciones termina con ella ejerciendo violencia física, en términos de Femenías (2009) pero aquí de una mujer hacia un varón con rasguños contra él: "se pone violenta", lo cual él no lo percibe negativamente, sino como parte de un juego donde ambos están interactuando lúdicamente y encontrando cierta satisfacción e intensidad. Según Porto (2014) citando a Gregori (1993) y a Grossi (1991, 1998), en las relaciones de violencia en los vínculos de pareja se diluye la imagen de un hombre agresor y aparecen imágenes que comprenden también a las mujeres como participantes activas de esos conflictos afectivos-conyugales.

Asimismo, en ese juego se puede rastrear el concepto de soberanía de Bataille, quien lo define como "gozar del tiempo presente sin tener en cuenta nada más que ese tiempo presente" (BATAILLE, 1996, p. 65). El lugar soberano o de cumbre, donde ambos se quieren afirmar como señores es también un lugar de perdición, ya que tiene como contraparte la posibilidad de pérdida del sujeto amado. En relación con el concepto de soberanía de Bataille, aunque si bien considero que algunos rasgos de la dinámica de la soberanía suceden dentro de estos noviazgos, retomo a Jane Gallop ${ }^{15}$ y a Gregori (2003), ya que me permiten complejizar este concepto. Para estas autoras, no hay mera soberanía. En la búsqueda de la intensidad, por ejemplo en una pelea, los miembros de la pareja generan complicidad e intensifican el lazo amoroso. Explica Gregori, "El éxtasis, como un estado en que se experimentar estar "fuera de si", es una idea que, antes de indicar una posición de soberanía o trascendencia, implica un lazo relacional (...) (GREGORI, 2010, p.42). ${ }^{16}$

Otro juego donde aparece la búsqueda de soberanía pero signada por el diálogo, la complicidad y disfrute, es decirse uno al otro con qué otras personas estarían. Pero esto tiene límites, la mentira.

E.: ¿Qué otros problemas tienen entre ustedes?

Gustavo: Y... ella, lo único malo que tiene es que es muy mentirosa.

E.: ¿Cómo sería eso?

Gustavo: No es que es mentirosa, como mentirosa que me puede cagar y me dice que no, porque sé que no me va a cagar nunca porque sé que no es así. Pero miente, o sea, hace mentiritas piadosas que me termino enterando, por ejemplo yo cuando la molesto

\footnotetext{
${ }^{15}$ Jane Gallop (1981) desarrolla una relectura del erotismo en Sade y revisa cómo fue interpretado por distintos autores, entre ellos George Bataille. Gallop considera a Batille como "el más obvio descendiente de Sade" (GALLOP, 1981, p. 7). Ambos, según Gallop, escribieron libros considerados como "sucios", según las sociedades de sus épocas, y se preocuparon seriamente por el problema del erotismo en relación con la existencia humana. No obstante, para Gallop, quien a su vez es retomada por Gregori (2003), explica que la teoría de Bataille enfatiza en la disolución de los lazos sociales y la soberanía absoluta de un sujeto con respecto al deseo. Mientras que Gallop encuentra en los textos del Marqués de Saque referencias a alianzas, solidaridad y regulaciones entre los libertinos.

16 "O êxtase, como estado em que o ser experimenta estar "fora de si", é uma ideia que, antes de indicar uma posição de soberania ou de transcendência, implica um laço relacional (...)" (GREGORI, 2010, p. 42) [Traducción propia]
} 
y le digo "ese chico te parece lindo" y me dice que no $y$ al otro día le digo el mismo chico y me dice que sí, y le digo ayer me dijiste que no y me dice "ayer te mentí" y nada, igual tuvimos un problema con eso que mentía. (...)

E.: ¿Como qué?

Gustavo: Le pregunto cosas de chicos, que me dice que no le pregunte como le pregunto que si no estaría más conmigo con quién estaría, y me lo dice y ella me pregunta "¿y vos?" y yo le digo...

E.: ¿Te dice con quién saldría?

Gustavo: Sí, me dice (...). Me dice nombre y apellido. Y cuando ella me pregunta yo le digo que "con nadie, porque sé que voy a estar con vos toda la vida" y se enoja porque es como que la cagué, como que no sé cómo expresarte.

E.: Contame con un ejemplo si no.

Gustavo: Ella me dice que por ahí cuando no esté más conmigo estaría con otro, con algún pibe, y yo le dije que con ninguna porque voy a estar siempre con ella. $Y$ ella como nada y después a los dos días me dice "no, porque vos me preguntaste" y me miente y qué sé yo.

En este fragmento se ve que él ejerce violencia psicológica (FEMENÍAS, 2009) al llevar a cabo un juego que si bien no implica romper con la promesa de fidelidad y monogamia que sustenta esta relación, se roza el límite porque se cuentan entre sí con quiénes desearían estar. Además, este juego potencia los celos de la pareja y les genera problemas si uno dice que no le pareció linda otra persona y luego dice que sí. La mentira es el límite del juego, comienza la escena del conflicto.

Será soberano en este juego quien responda con la verdad. Aquí Gustavo, para lograr colocarse como amo, le juega una mala pasada a ella, tal como él dice: "la cagué", porque primero hace quedar en evidencia que ella mintió (un día dijo que no le gustaba otra persona y al otro día dijo que sí) y le responde que él sólo está interesado en ella. Si bien a simple vista, pareciera que es él quien sale victorioso de la escena, como señor, y ella como súbdita por haber mentido y ser quien desea estar eróticamente con otros varones, retomando la propuesta teórica de Gallop y Gregori, en esta búsqueda de soberanía no hay una apuesta por la ruptura del lazo de pareja. Más bien, a partir de este juego, la pareja reafirma los lineamientos románticos que constituyen a su pareja, en este caso la fidelidad. ${ }^{17}$

En este juego se materializa una tensión. Por un lado, les brinda placer, goce, les genera complicidad, risas y diversión; $y$, por el otro, conflicto, debido a que, por el resultado de ese juego, él considera que ella es una mentirosa, lo cual le trae problemas a la relación.

Los golpes como un juego, aunque en el siguiente caso más severo, también se encuentran en la relación de Lara, que tenía 19 años al momento de la entrevista con su ex pareja. Ella, si bien en el momento de la entrevista no se encontraba más de novia con esa persona, comenta una escena en la cual jugaban a golpearse de puños con su ex novio. La misma puede ser catalogada como violenta en los aspectos psicológicos y físicos.

Lara: Los dos nos decíamos cosas hirientes. Yo jamás le dije algo como inútil o mongólico, o no sé. Le decía capaz lo más feo es para qué carajo estoy con vos o si lo único que me hacés es mal, cosas así. Y nada, terminábamos también, violentos los dos. Ya me acuerdo, después cuando empezamos con todo eso, capaz que estábamos bien, pero siempre que nos emborrachábamos empezábamos a pelear, en broma, pero terminábamos hechos mierda, después "ay sí vení mi amor", pero yo toda lastimada, el chabón todo lastimado, ¿entendés?

\footnotetext{
${ }^{17}$ Para Gallop (1981) no habría soberanía dado que para la autora el diálogo, como opuesto al silencio, es antitético a la soberanía.
} 


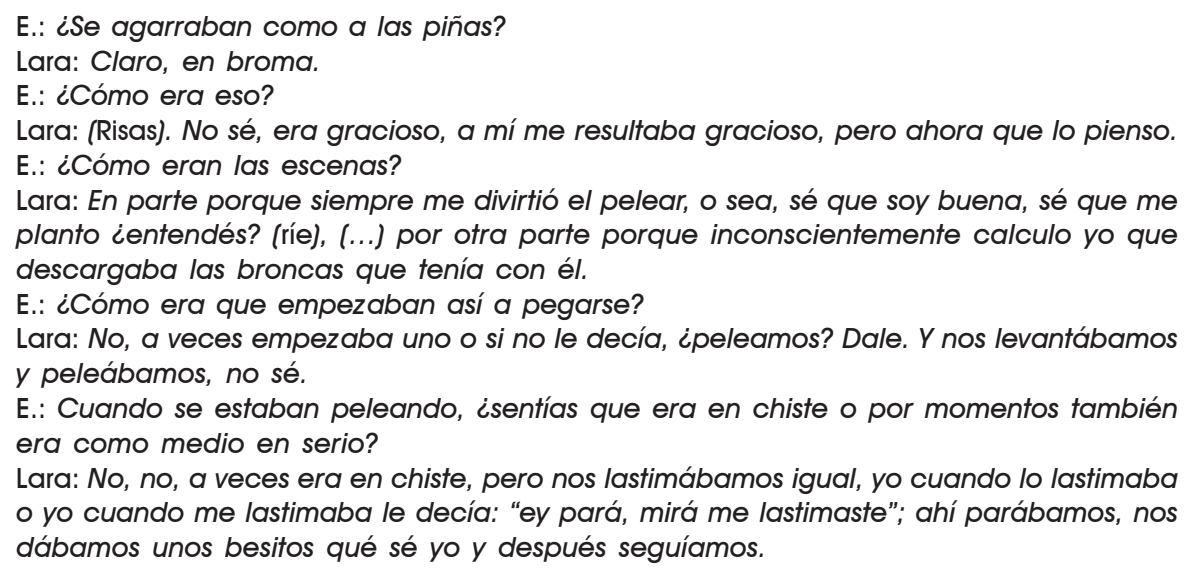

En este fragmento de Lara hay juegos que podrían ser catalogados como violentos porque incluyen golpes y dejan marcas visibles sobre los cuerpos. En esa interacción participan ambos y allí Lara no se presenta como en una posición inferior respecto a su novio varón, sino que dice que es buena y que "se planta", es una mujer que resiste a la perpetración de la violencia de su pareja y que responde del mismo modo.

Por un lado, encuentran en ese juego una forma de canalizar insatisfacciones (GREGORI, 1993): su novio la menospreciaba y ejercía violencia verbal, aunque ella también actuaba de la misma forma cuando le decía "para qué carajo estoy con vos". Ambos retroalimentan de este modo una interacción violenta (OSBORNE, 2008) porque pese a que ella aducía que le hacía mal, se aceptaban en el tiempo que duró la relación (GOFFMAN, 1971).

Por otro lado, esta práctica que es comentada como un juego y como una escena de complicidad entre la pareja puede ser catalogada como violenta. El límite a ese juego de violencia/amor era cuando se lastimaban. El modo que tenían de compensar esa extralimitación era a partir de la gestualidad amorosa, como por ejemplo un beso, que los habilitaba a reanudar la gestualidad violenta. En ese caso paraban el juego de puños, se besaban para luego reanudarlo. Desde ese lugar volvían a su juego de golpes en el cual, identificándose como iguales, resolvían broncas (GREGORI, 1993), se divertían y entraban en comunicación (BATAILLE, 2010). Si bien esta interacción responde a un registro violento, era vivido por ellos como parte del amor.

Por último, para Tamara y Hugo, que llevaban al momento de la entrevista dos años y siete meses, también las peleas son parte cotidiana de su noviazgo. El escenario de la entrevista (PAIVA, 2006) fue un café en una zona céntrica de la Ciudad de Buenos Aires a la hora de la cena, luego de que salían de la escuela. Van al turno nocturno. Nos sentamos en una mesa de a tres. Él frente mío y ella a mi costado. Apenas encendí el grabador pude observar lo fragmentario y discontinuo de su discurso amoroso (BARTHES, 2001; BATAILLE 2010; GREGORI, 1993, 2003), saltaban de un tópico a otro. Dentro de esos tópicos se ubican algunos cercanos a prácticas y temáticas vinculadas al registro de lo amoroso y otros a la violencia. Hugo comenzó a decirme, vehementemente, delante de Tamara, todo lo hiriente que era su novia con él, a la vez que ella le discutía lo que él decía. Tuve que interrumpir la entrevista en diferentes situaciones y pedirles que por favor se tranquilizaran y bajaran tono de voz. Las personas que estaban en las mesas del bar, alrededor de la nuestra, pausaban sus diálogos y nos observaban. Estas discusiones, gritos y golpes a la mesa terminaban 
rápidamente en besos y abrazos. Esta dualidad - discusión/reconciliación, gritos/besos, amor/odio - era manifestada y expresa con igual intensidad.

Hugo: O sea, vos lo habrás notado, viste cómo empezó esta conversación y cómo terminó, así es todos nuestros días, así, o sea, un día nos amamos y otro día nos odiamos.

Tamara: No, todos los días nos amamos.

Hugo: Claro, todos los días nos amamos, pero algunos nos odiamos también.

Tamara: No, yo te voy a decir algo, te voy a decir la verdad, a mí me gusta pelearme, me divierte, me encanta pelearme.

Hugo: $Y$ yo lo tomo a pecho, entonces termina todo en un quilombo.

El modo en que ella percibe las peleas es como un juego, una diversión; en cambio, para él no, lo cual genera conflictos. No obstante, él es parte de ese juego al continuar la interacción y marcar esa intensidad como límite de lo aceptable en su vínculo amoroso.

En este apartado, me propuse abordar a partir de tres historias amorosas dinámicas de violencia que son percibidas por los jóvenes lúdicamente, en el marco del amor y como parte de sus interacciones cotidianas.

\section{Las quejas y las reconciliaciones}

En este apartado indago sobre experiencias de búsqueda de convergencia, en términos de Gregori (1993), es decir, conflictos que terminaron en una reconciliación, y analizo cómo las escenas de conflicto son relatadas por los/as entrevistados/as como quejas.

Para dicho fin, analizo la entrevista a Pedro, la de la pareja de Daniela y Germán y la de Gabriela.

Pedro tenía 17 años al momento de la entrevista y estaba de novio hacia un año y diez meses al momento de la entrevista. Él, por su militancia, en la cual se forma sobre temáticas vinculadas al género y la sexualidad, estaba informado sobre la violencia contra las mujeres y a lo largo de la entrevista marcó distancias entre lo que él considera como violencia de género y las situaciones de discusión dentro de su pareja. Aunque reconoce, a pesar suyo, que a veces la dinámica de los conflictos con su novia a veces rozaba lo violento.

E.: ¿Tuvieron alguna experiencia que pienses que fue violenta? Pedro: Violenta no. Una vez sí medio que nos gritamos de más. Estábamos en el bar y ella fue a poner una canción en la rocola y no se le marcaba, no se le marcaba, no sé por qué, y se puso una chica atrás y le empezó a tocar pensando que ya había puesto el tema y yo le dije "ya está amor, ya se puso en la lista de espera" porque ya habían puesto antes. Ella se quedó mirándola medio caliente. Estaba caliente por cómo se había puesto por una boludez, le dije "¿qué pasa, la vas a cagar a piñas?". Obviamente no pero se lo dije en tono irónico. Y se enojó y le dije que si quería ir y nos fuimos y se enojó más porque en realidad ella no se quería ir y cuando subimos al auto, porque ella tiene auto, medio que arrancó a los pedos y le dije: "Qué te pasa loca, cómo vas a arrancar asi" y ella se puso peor. No es que nos puteábamos y nos decíamos "sos un estúpido" pero sí un nivel de agresividad, así, verbal. Nos calentamos en el momento, igual se sentó en el cordón, pasaron cinco minutos y volvimos a la casa después. Pero llegamos a la casa y hablamos un toque y después lo arreglamos. Los dos sabíamos que nos habíamos expresado mal y que habíamos reaccionado mal.

En este fragmento también se puede encontrar una tensión entre agresión y amor. La escena de discusión transcurre con el siguiente ritmo (PAIVA, 2006). Primero, él le hace un chiste de modo irónico, lo cual linda entre lo cordial y lo agresivo dado que él solía hacerle 
bromas que a ella no le gustaban. Por la reiteración, esta práctica puede ser catalogada como una forma de violencia psicológica (VELÁZQUEZ, 2009). En un segundo momento ambos reaccionan mal. En lugar de cortar esa interacción (GOFFMAN, 1970), finalmente se van juntos en el auto. Esto en vez de devenir una escena de reconciliación, genera una escena de violencia donde ella maneja a gran velocidad, marcando la intensidad en la que se encontraba la situación. Ante este panorama, él reacciona gritándole (violencia verbal). Esta escena de discusión, deviene en un tercer momento de mayor intensidad de la pelea donde ella frena el auto, le recrimina haberse tenido que ir del lugar donde estaban y llora.

\section{E.: ¿Ella qué te respondía?}

Pedro: Ella no estaba tan agresiva, sí hablaba en voz alta. Decía: "¿Qué te pasa a vos?", cosas así y al toque se bajó y se sentó en el cordón sola.

E.: ¿Las charlas quién las encaró?

Pedro: Fueron diversas charlas y los dos las fuimos encarando, fuimos encarando problemas distintos y ahora ya no. Yo puedo decirle tal cosa o ella puede decirme tal cosa y discutirlo bien.

E.: ¿Por qué se venían llevando mal?

Pedro: ¿Por qué nos peleábamos? Era esa sensación de sentir que me lo decía para recriminármelo y yo sentirme culpable y estar maquinándome.

La situación se resolvió luego a través de una charla, desde el diálogo, ${ }^{18}$ propio de la racionalidad del ámbito homogéneo (BATAILLE, 2003) y acorde con el modelo de amor comunicativo que se contrapone al amor pasional (ILLOUZ, 2009), que es adonde debe apuntar el amor para Margarita Camarena Luhrs (2010). Sin embargo, él identifica que cuando las discusiones con su novia se tornan más fuertes ella llora, ante lo cual él se siente culpable. Cuando Pedro dice que su novia lo deja "maquinando", está exponiendo una queja. La queja se caracteriza por una exteriorización que busca la culpa en el otro (GREGORI, 1993) y demostrar que él desempeña correctamente, dentro de sus representaciones sobre el amor, su papel como novio, es afectuoso y trata de entenderla. Él siente que ella, con su queja, quiere hacerlo sentir culpable.

Este tipo de interacción, "dejarlo maquinando", en su reiteración, puede ser identificada como una práctica psicológicamente violenta de ella hacia él (OSBORNE, 2009).

E.: Cuando vos discutías con ella, ¿encontrabas intensidad ahí?

Pedro: No mucho porque como ella se siente afectada muy rápido, cuando ella se pone a llorar o se pone mal tipo yo me siento mal por hacerla sentir mal y bajo. Pero sí nos ha pasado que alguna u otra vez, los dos de empezar a discutir por algo y cebarnos pero no de discusión mal, discusión bien, hablando de política, cualquier cosa, nos cebamos y ahí empieza a subir la intensidad de la discusión. Pero en cuanto a peleas no porque en cuanto ella se ve afectada o yo me veo afectado tipo baja la intensidad.

En el caso de esta pareja, el llanto de ella funciona marcando el parámetro de lo permitido como violento en su interacción y marca el paso al momento de la reconciliación.

En la pareja de Germán y Daniela, que tenían 18 años y estaban en pareja hace un año y cuatro meses al momento de la entrevista, luego de una discusión a causa de que uno leyó mensajes del Facebook del otro sin pedir permiso - en la cual hubo violencia verbal (FEMENÍAS, 2009) -, vino la escena de placer (BARTHES, 2009; GREGORI, 2003), de comunicación tan fuerte como fue la escena de discusión.

${ }^{18}$ El diálogo es nombrado por el entrevistado como un modo de solución de conflictos, de comprenderse, no en el sentido que le da Barthes (2009) cuando se presenta dentro del conflicto como ejercicio de un derecho mediante el cual cada uno a su turno dice lo que quiere decir sin implicar que se escuchen. 


\section{E.: ¿Qué te dijo cuando te criticó?}

Daniela: Me dijo "no porque vos sos una, sos un desastre, no podés, no podés".

Germán: No, porque vos empezaste a mirar la conversación.

Daniela: "No podés, no podés, sos, no podés hacer eso de mirar conversaciones ajenas, sos una maleducada, no sé qué".

Germán: Pero vos empezaste a leer la conversación.

Daniela: No tenés educación (hablan uno sobre el otro).

Germán: Vos empezaste a leer la conversación, yo no, yo cuando veo que está abierta la conversación con tal persona y listo.

Daniela: Sí, claro, está bien, está bien (tono irónico). Es lo mismo Germán.

Germán: Está bien, sí. Al fin y al cabo es lo mismo pero qué sé yo.

Daniela: Entonces no tenías por qué criticarme así. Me empezaste a putear, me re puteaste, me puteó, me dijo que era una pelotuda, que era una forra que podía mirar conversaciones así, que era una maleducada, bla bla bla. Un montón de cosas y no era tan grave porque vos dejaste el Facebook abierto en mi casa en definitiva, no hubieras abierto nunca tu Facebook.

Germán: Bue, lo cerrás y listo.

Daniela: iNo, no hubieras abierto nunca tu Facebook! Fin.

Germán: Eh... no, no me acuerdo qué iba a decir ahora. Pero, iba a decir algo pero no me acuerdo ahora.

E.: No se hagan problema. Y después, la resolución de los conflictos ¿Qué hacen? Germán: Por ejemplo, a veces sí terminamos un conflicto, en vez de yo tener que irme a mi casa por ejemplo, me quedo con ella y nos quedamos juntos, como que resolver un problema te hace dar cuenta, darte cuenta de que estás como más unido cada vez, yo siento eso.

Daniela: Claro, como que te unís después de, después del conflicto como que te arreglás $y$ es como que te querés quedar con la persona, capaz a veces como que él se está por ir o estamos re peleados y es como que "bueno, andate" y cuando nos arreglamos, se queda, y nos quedamos ahí.

De este fragmento se desprenden varios aspectos. En primer lugar, cuando recuerdan el conflicto comienza una nueva discusión, la cual pude observar, donde el derecho al diálogo, en términos de Barthes (2009), existe hasta cuando ella le dice "Fin" y él ya no puede retornar al punto de lo que iba a decir. Esa escena (GREGORI, 1993) se monta a partir de una queja (GREGORI, 1993), es decir, cuando Daniela me comenta a mí su infortunio, en este caso lo que le dijo Germán "Me dijo "no porque vos sos una, sos un desastre, no podés, no podés". La queja deviene rápidamente una discusión, el motivo inicial se pierde, lo que pasa a importa es relatar una situación de sufrimiento causada por la pareja y enfatizar la gravedad de cómo la hizo sentir el otro.

La queja deviene en una escena de pelea (PAIVA, 2006) que adquiere una velocidad rápida. Uno habla encima del otro y se discuta un hecho puntual: la gravedad del modo en que cada uno leyó el Facebook del otro. Las respuestas se mueven en cierta simetría (BARTHES, 2009), pero cada uno focaliza su yo, como si lo que sintió o su propia situación hubiera sido más grave, aunque se basó en el mismo hecho: ambos leyeron conversaciones del Facebook del otro.

En segundo lugar, según el entrevistado, en el proceso de la reconciliación se encuentra la satisfacción y el deseo de continuar aún más la relación. Son momentos de fusión (BATAILLE, 2010) que aportan a un "progreso", a una construcción de la pareja (BADIOU, 2010). Una fusión a partir de la cual las diferencias entre los miembros de la pareja aparecen primero enfatizadas para, en seguida, ser disueltas y negadas (GREGORI, 2010). La resolución del conflicto se da a través de dos medios posibles: quedarse juntos, es decir, el pasaje al deseo (BARTHES, 2009), o si no el diálogo que es propio de la racionalidad del ámbito 
homogéneo. Aquí el diálogo, a diferencia de la concepción del mismo descripta por Barthes (2009) que se da dentro de una escena de discusión, busca el entendimiento.

En tercer lugar, al revisarse el Facebook, estos jóvenes restablecen su pacto amoroso. A partir del control, lo cual es una práctica violenta, ambos pueden visualizar que ninguno está fallando al pacto constitutivo de su relación, la fidelidad, propia del amor romántico. Es decir, fortalecen sus representaciones y sentidos en relación con la pareja y el amor, desde un registro que la perspectiva de autoras como Femenías (2006) y Velázquez (2009) presuponen por fuera del orden de lo amoroso.

La última experiencia que analizo aquí es la de Gabriela, quien tenía 18 años al momento de la entrevista, y estaba hace cuatro meses de novia. En este caso, ella busca, a través de medios virtuales, estar comunicada con su novio cuando él sale de noche, por miedo a que le sea infiel.

Gabriela: Nada, soy bastante goma, goma de que pienso todo, todo el tiempo todo el día de por qué no me habla, igual no es que le rompo tanto las pelotas pero estoy todo el día pensando y le cuento a las pibas eso un poco. Pero después nada, le rompo las bolas.

E.: ¿A él le rompés las bolas? ¿Cómo es eso?

Gabriela: No sé, por ejemplo sale a la noche, no es que le rompo las bolas de novia loca, sino de que nada. El pibe es si sale yo salgo y lo que hace que me rompe las bolas es que me clava vistos en el WhatsApp, o sea, le pongo: "¿che qué onda? ¿Salís?". Ahora ya aprendí igual porque ya entendí que nada, ya fue, yo debería estar disfrutando lo que yo hago, pero fue un proceso. Así horas, y yo me empiezo a violentar más corte, no me va a contestar nunca, así de decirme "che Gabi la verdad que sos una goma", o sea pará. Y así todo el día, de que estoy medio chiflada. (...)

Es incómodo. O sea, a mí me encantaría estar más tranquila porque en realidad estoy tranquila, tengo novio, no es que tengo un pibe que quizás me caga, quizás no me caga y nada, podría salir tranquila y decir mi novio salió, lo veo mañana ¿entendés?, en vez de estar como una pelotuda, que me hace mal, todo el tiempo pensar.

E.: ¿Cuando él te "clavaba el visto", vos qué hacías después si él no te respondía? ¿Qué te pasaba?

Gabriela: Nada, después me respondía, pero a las 5 horas ientendés?

E.: ¿En esas cinco horas estabas todo el tiempo pensando?

Gabriela: No, me enojaba. Pero sí, igual con las pibas yo soy así, o sea, estoy enojada y les puedo decir a mis amigas, todo el tiempo estoy hablando de él, pero sí estoy medio mal con eso.

Ella describe la intensidad de su vínculo al punto de la obsesión. Ella se queja de que su novio no le responde los mensajes de Whatsapp cuando sale de noche y eso la deja "todo el día pensando". Ella se expresa a partir de su queja como víctima. Su novio rompió con aquello que estos actores esperan de su desempeño como novios: estar uno atento al otro y dar la seguridad de que son fieles. Él sabiendo que ella quiere saber de él, no le responde, es decir, actúa ignorándola, no sólo en esta situación sino también cuando no quiere besarla en la plaza ante la presencia de otras jóvenes que "gustan" de él. ${ }^{19}$ Este

${ }^{19} \mathrm{E} .:$ ¿Qué otro problema habitual tienen?

Gabriela: Ah, eso fue porque... nada, tema romanticismo pelotudo de que yo... Fue un momento en el que yo estaba más hasta las bolas que él en el noviazgo y yo no lo notaba más porque hacía cosas que nada que ver. (...) Como estar acá y no saludarme enfrente de dos pibas que gustaban de él y decirle corte bue, pará. Yo de venir acá y decirle: "Loco, hola. Podemos estar sin besarnos, pero saludame" (...) le digo mirá, si vos vas a mantener cosas haciendo que yo no estoy de novia con vos bueno, y esas cosas me hacían sentir que el chabón no estaba como yo estaba porque la verdad es que cuando ves a tu novio tenés ganas de saludarlo no importa con quién esté. 
ignorar al otro y hacerlo esperar, a partir de lo que he venido presentando, puede ser conceptualizado como violento (VELÁZQUEZ, 2006).

Dentro de los parámetros de esta relación, las acciones de él repercutían excesivamente en los estados de ánimo de ella, piensa excesivamente en él, les habla excesivamente a sus amigas sobre él y aunque no le manda mensajes de texto todo el tiempo, hay un exceso en ese canal de comunicación. Gabriela dice que le "rompe las pelotas". Estos excesos, propios del erotismo (BATAILLE, 2010), se basan por un lado en el interés de saber acerca del otro y aportar a la construcción (BADIOU, 2009), pero por el otro en la desconfianza que le genera que su novio salga de noche.

El hecho de que el novio de Gabriela la haya hecho esperar en su respuesta, en saber que de él, y en besarla no implica que ella no lo haga esperar, en un mismo sentido. Pero sí, desde una perspectiva de género, se puede analizar cómo las mujeres poseen reflexiones más acabadas y son más expresivas acerca de sus emociones, en detrimento a los varones. Para comprender mejor este punto, retomo el análisis que hace Eva Illouz (2009) sobre las emociones, sobre todo las afectivas, en las parejas heterosexuales.

Según Illouz (2009), las emociones afectivas se encuentran insertas dentro de un discurso del amor que se ha "feminizado". Para ser románticos, retoma a Francesca Cancian (1987) y explica, "los hombres deben hacer a un lado (temporalmente) el control de las emociones y la firmeza de la autoridad, cambiando esas cualidades por otras como la 'delicadeza', la 'candidez' y el 'cuidado'. Las mujeres, por su parte, sólo deben seguir siendo lo que son 'por naturaleza'” (ILLOUZ, 2009, p. 150). De este modo, la imagen del romance neutraliza las diferencias de género, dado que coloca tanto a los varones y a las mujeres dentro de la esfera femenina de los sentimientos. No obstante, desde una perspectiva de género, discuto en parte con el análisis que desarrolla la autora. En las entrevistas, aparece que los varones no hacen referencias extensas y descriptivas a esperas en el amor desde un discurso feminizado, aunque esperan. Entiendo que las mujeres, en el discurso del amor romántico, son quienes desarrollan reflexiones acabadas sobre sus (des)amores y expresan más los sufrimientos que les generan los conflictos amorosos.

\section{Conclusiones}

En este trabajo me propuse indagar en diferentes nociones sobre amor y violencia, para mostrar cómo no existe una categoría unívoca que permita explicar las dinámicas del amor y la violencia en los jóvenes, sino que coexisten diversos valores, que, aunque contradictorios, conforman el modo de amar estos jóvenes. Algunos de los preceptos amorosos de los/as entrevistados/as están atravesados por la entrega, la afectividad corporal, la desconfianza, los celos y control, como así también la simetría en ciertas cuestiones en relación con lo sexual y económico, que si bien aquí no fue desarrollado, emergió durante el trabajo de campo de la investigación.

En el desarrollo de las escenas se puede visualizar cómo cada uno de los miembros ejerce violencia sobre el otro. No hay meros receptores, sino que cada uno de los integrantes moldea violencias específicas, según el género, sobre el otro. Los diferentes elementos que configuran sus pautas de cortejo y noviazgo hacen que la violencia no sea considerada por los/as entrevistados/as estrictamente en términos negativos, sino como modos de alcanzar complicidad, satisfacción recíproca, diversión y fusión. Es decir, encuentran en el erotismo un vaivén entre el registro de lo homogéneo y de lo heterogéneo.

Las escenas que comienzan con agresiones pueden dar lugar a escenas de placer - a la inversa, interacciones cercanas a lo lúdico pueden derivar en agresiones. Pero las resoluciones a los conflictos serán de índole amorosa. Es decir, las escenas marcadas por 
la comunicación fuerte permiten el pasaje efusivo de estados de divergencia a aquellos de reconciliación.

Bajo la égida de estas tensiones, podemos preguntarnos ¿cuáles son sus límites de lo tolerable bajo el lema del amor? Aunque en las entrevistas pude rastrear ciertos límites, a saber, el llanto o los golpes contra objetos o paredes, este interrogante es difícil de establecer, dado que los jóvenes se encuentran en la búsqueda de vínculos auténticos signados por nuevas intensidades y de fusión con sus pares.

Por último, en este trabajo me propuse aportar a los estudios sobre la violencia contra las mujeres nuevas herramientas que apunten a un análisis más amplio sobre las dinámicas, los juegos y las interacciones amorosas. Resulta indispensable si se quiere pensar y/o prevenir la violencia en las parejas tener en cuenta cómo la violencia es un modo de erotización en estos sujetos jóvenes de clase media urbana.

\section{Referencias}

BADIOU, Alain y TRUONG, Nicolas. Elogio del amor. Buenos Aires: Paidós, 2012.

BARTHES, Roland. Fragmentos de un discurso amoroso. Buenos Aires: Siglo XXI, 2009.

BATAILLE, Georges. El erotismo. Buenos Aires: Tusquets, 2010 [1957].

BATAILLE, Georges. "La noción de gasto". En: BATAILLE, Georges. La parte maldita. Barcelona: Editorial ICARIA, 1987 [1967].

BATAILLE, Georges. "La estructura psicológica del fascismo". En: BATAILLE, Georges. Obras escogidas. Barcelona: Barral Editores, 2003 [1974].

BATAILLE, Georges. La literatura y el mal. Ediciones el aleph, 2000 [1955].

BATAILLE, Georges. Lo que entiendo por soberanía. Barcelona: Paidós, 1996 [1976].

BUTLER, Judith. Cuerpos que importan. Sobre los límites materiales y discursivos del "sexo". Buenos Aires: Paidós, 2002.

BUTLER, Judith. El género en disputa. El feminismo y la subversión de la identidad. Madrid: Paidós, 2007.

BOURDIEU, Pierre. La dominación masculina, Buenos Aires: Página/12, 2010.

CAMARENA LUHRS. Margarita, "Amor, interiorización del poder". En: CAMARENA LUHRS, Margarita (Coord.). Amor y Poder. Chiapas: Universidad Intercultural de Chiapas / Razón y Acción A.C., 2010.

CANCIAN, Francesca. Love in America. Cambridge: Cambridge University Press, 1987.

CONNELL, R. W.. "The Social Organization of Masculinity". En: CONNELL, R. W. Masculinities. Berkeley: University of California Press, 1995.

COSSE, Isabella. Pareja, sexualidad y familia en los años sesenta. Buenos Aires: Siglo XXI, 2010.

DÁVILA LEÓN, Oscar. "Adolescencia y juventud: de las nociones a los abordajes". Última década, n. 21, Santiago de Chile, diciembre 2004.

ELIZALDE, Silvia. "El androcentrismo en los estudios de juventud: efectos ideológicos y aperturas posibles". Última Década, v. 14, n. 25, p. 91-110, diciembre 2006.

FEMENIAS, María Luisa y SOZA ROSSI, Paula. "Poder y violencia sobre el cuerpo de las mujeres". Sociologías, n. 21, p.42-65, junio/julio 2009.

FEMENÍAS, María Luisa y APONTE SÁNCHEZ, Elida. "Violencia contra las mujeres: urdimbres que marcan la trama". En: FEMENÍAS, María Luisa y APONTE SÁNCHEZ, Elida (Coord.). Articulaciones sobre la violencia. La Plata: Universidad de la Plata, 2008.

FROMM, Erich [1959]. El arte de amar, Buenos Aires: Paidós, 2004.

GALLOP, Jane. Intersections. A Reading of Sade with Bataille, Blanchot and Klossowski. Lincoln: University of Nebraska Press, 1981.

1344 Estudos Feministas, Florianópolis, 25(3): 1329-1346, setembro-dezembro/2017 
GALLOP, Jane. Thinking through the body. New York: Columbia University Press, 1988.

GOFFMAN, Erving. La presentación de la persona en la vida cotidiana. Buenos Aires: Amorrortu, 1971.

GOFFMAN, Erving. Ritual de la interacción. Buenos Aires: Tiempo Contemporáneo, 1970.

GREGORI, María Filomena. Cenas e Queixas - um estudo sobre relações violentas, mulheres e feminismo. São Paulo: Paz e Terra / ANPOCS, 1993.

GREGORI, María Filomena. "Relações de violência e erotismo". Cadernos Pagu, v. 20, p. 87 120, 2003.

GREGORI, María Filomena. Prazeres perigosos. Erotismo, gênero e limites da sexualidade. 2010. Tese Apresentada ao concurso de Livre-docência departamento de AntropologiaInstituto de Filosofia e Ciências Humanas Universidade Estadual de Campinas

GROSSI, Miriam. "Vítimas ou Cúmplices? Dos diferentes caminhos de produção acadêmica sobre violência contra a mulher no Brasil". Caxambú-XV Encontro Anual de ANPOCS, 15 a 18 de outubro de 1991.

GROSSI, Miriam. "Rimando amor e dor: Reflexões sobre a violência no vínculo afetivoconjugal". En: PEDRO, Joana; GROSSI, Miriam (Orgs.). Masculino, Feminino, Plural. Florianópolis: Mulheres, 1998.

ILLOUZ, Eva. El consumo de la utopía romántica. Buenos Aires: Katz, 2009.

ILLOUZ, Eva. ¿Por qué duele el amor? Una explicación sociológica. Buenos Aires/Madrid: Katz, 2010.

KAPLÚN, Gabriel. “Imágenes del cuerpo joven”. Revista Punto Cero, v. 9, n. 9, 2004. Disponible en: $\quad$ http://www.scielo.org.bo/scielo.php?script=sci_arttext\&pid =S 1815 02762004000200003.

MARGULIS, Mario y URRESTI, Marcelo. "La juventud es más que una palabra". En MARGULIS, Mario (Eds.). La juventud es más que una palabra. Buenos Aires: Biblos, 1994.

MARGULIS, Mario. Juventud, cultura, sexualidad. Buenos Aires: Biblos, 2003.

OSBORNE VERDUGO, Raquel. "De la "violencia" (de género) a las "cifras de la violencia": una cuestión política". Revista de Metodología de Ciencias Sociales, n. 15, p. 75-98, enero/junio 2008.

OSBORNE VERDUGO, Raquel. "Construcción de la víctima, destrucción del sujeto: el caso de la violencia de género". En: Jornadas Feministas de Granada, 5-8 diciembre de 2009. Disponible en: http://www.feministas.org/IMG/pdf/Mesa_Violencia_Raquel_Osborne.pdf.

PAIVA, Vera. "Analisando cenas e sexualidades: a promoção da saúde na perspectiva dos direitos humanos". En: CÁCERES, Carlos; CAREAGA, Gloria; FRASCA, Tim; PECHENY, Mario (Eds.). Sexualidad, estigma y derechos humanos: desafíos para el acceso a la salud en América Latina. Lima: FASPA/UPCH, 2006. p. 23-52. Disponible en: http:// www.bdigital.unal.edu.co/47322/1/9972806251.pdf.

PALUMBO, Mariana. Las dinámicas de la violencia contra las mujeres y el amor en los primeros noviazgos juveniles en el Área Metropolitana de Buenos Aires. 2015. Tesis de Maestría en Investigación en Ciencias Sociales - Facultad de Ciencias Sociales de la Universidad de Buenos Aires.

PORTO, Rozeli Maria. Gravidez e relações violentas: representações da violência doméstica no município de Lages. Natal: EDUFRN, 2014.

RAMIREZ-RODRÍGUEZ, Juan Carlos. "La violencia de varones contra sus parejas heterosexuales: realidades y desafíos. Un recuento de la producción mexicana". Revista Salud Pública, v. 48, suplemento 2, p. 315-327, enero 2006. Disponible en <http:// www.scielo.org.mx/scielo.php?script=sci arttext\&pid=s0036$36342006000800012 \& \mathrm{lng}=e s \& n r m=i s o>$. Acceso el: 6/6/2017. 
SCOTT, Joan. "El género: una categoría útil para el análisis histórico". American Historical Review, n. 91, p.1053-1075, 1986.

SCOTT, Joan. "Experiencia". En: BUTLER, Judith y SCOTT, Joan W. (Eds.). Feminists Theorize the Political, reproducido con el permiso de Routledge Inc., que es parte del Grupo Taylor \& Francis, 1992.

SIMMEL, Georg. Sociología. Estudios sobre las formas de socialización. Buenos Aires: Espasa Calpe, 1939.

VÉLAZQUEZ, Susana. Violencias cotidianas, violencia de género. Escuchar, comprender, ayudar. Buenos Aires: Paidós, 2006.

[Recebido em 24/12/2015, reapresentado em 13/09/2016. e aprovado em 10/01/2017]

Experiences of Love and Violence in the First Young Dating Relationships

Abstract: The hypothesis of this research is based on the existence of a tension between violence and love during the first dating relationships of heterosexual middle-class young people, from Buenos Aires Metropolitan Area (AMBA). In order to address this hypothesis, a theoretical and methodological proposal that allows to problematize and interrelate both concepts is developed. Afterwards, in the light of that perspective, the work analyzes both scenes of violence that are framed, from the perspective of the actors, inside a record of game and love, and scenes that allows to visualize the passage from moments of fight to moments of pleasure within the couple. Key words: violence against women; love; agency; intensity

Mariana Palumbo (mrnpalumbo@gmail.com) es socióloga y maestra por la Universidad de Buenos Aires, donde también realiza actualmente el doctorado en Ciencias Sociales con una beca expedida por el Consejo Nacional de Investigaciones Científicas y Técnicas. Sus principales líneas de investigación son sobre los estudios de las emociones, amor romántico, violencia, género y sexualidad. Es miembro del grupo de estudios "Sexualidad, Salud y política en América Latina: reconstrucción y análisis de una tradición intelectual en investigación" y del Programa contra la Violencia de Género de la Universidad Nacional de San Martín.

1346 Estudos Feministas, Florianópolis, 25(3): 1329-1346, setembro-dezembro/2017 